\title{
A RENASCENÇA DE MICHELET \\ A TAREFA PEDAGÓGICA DO HISTORIADOR DIANTE DE SEU POVO
}

Gabriela Rizo ${ }^{1}$

Resumo: Através dos conceitos de Renascimento e de Povo, na obra de Jules Michelet, é possível observar a coligação entre a atividade do historiador e a produção de uma escrita da história que visa ser responsável e útil à vida. Este artigo procura refletir acerca da manifestação do historicismo romântico em Michelet, bem como sua idealização do historiador enquanto pedagogo, capaz de ensinar a auto-estima e a valorização da tradição.

Unitermos: Jules Michelet, Lucien Febvre, Renascença, historiografia romântica, ação pedagógica.

O foco das preocupações de Jules Michelet em sua obra sempre foi o homem enquanto agente histórico. Em face ao mundo do século XIX, o principal objetivo micheletiano foi demonstrar que a História não tem uma propositoriedade em si mesma, mas é construída por agentes humanos. Como historiador romântico, pode-se atribuir a Michelet aquilo que, segundo Michael Löwy, caracteriza todos os tipos de romantismos oitocentistas: a resistência ao mundo capitalista que se configura em sua época (LÖWI e SAYRE, 1993). Na visão micheletiana, o mundo capitalista é a grande causa da massificação do povo francês, e, assim, da submersão de um espírito autônomo. Michelet vê a solução para isso na revigoração da liberdade dos povos, e na superação da

${ }^{1}$ Mestre em História pela Pontifícia Universidade Católica do Rio de Janeiro. 
mediocridade, através da recuperação das tradições revolucionárias. Nesta perspectiva, a idéia de regeneração de valores latentes em seu povo é de grande importância.

Para analisar tal característica da obra de Michelet, o livro de Lucien Febvre, "Michelet e a Renascença ", torna-se uma obra de grande importância, uma vez que busca unificar o conceito de Renascimento, em Michelet, com sua perspectiva quanto ao papel do historiador, e suas posturas quanto ao significado da História para o povo. A análise de Febvre só vem a comprovar que nenhum conceito em Michelet existe sem a idéia de povo. Em seu livro, "O Povo", este autor revela a cada momento, com sua escrita, seu objetivo em fazer renascer a força dos franceses, despertada através da história.

Lucien Febvre parte da idéia que conceito de Renascença seria "inventado" na França por Jules Michelet no século XIX. Segundo Febvre, Michelet criou o conceito de Renascença entre 1840 a 1842, revelando a convicção de que a escrita da história age na construção do espírito francês. O Renascimento, para Michelet, atuaria como representação da possibilidade de um renovar-se constante na História vivida, ou seja, uma ressurreição dos sujeitos históricos do século XIX.

Febvre coloca que o conceito de Renascença, como conceito de época, teria sido utilizado pela primeira vez em um curso ministrado por Michelet. Para o fundador dos Annales todas as idéias de Renascença que existiram antes do conceito desenvolvido por Michelet eram fragmentadas e não se direcionavam a um momento histórico abrangente. Referiamse, por outro lado, a momentos específicos, na maioria das vezes no campo das artes. Portanto, antes de Michelet não existia a Renascença, como momento histórico específico, a sim as renascenças. Em Michelet, o conceito de Renascença ganha completude enquanto conceito histórico que abrange uma época onde o homem de gênio é capaz de produzir ação, suplantando a Idade Média e caminhando para uma revolução, a supremacia do espírito humano. 
Como romântico, Michelet apresenta uma visão de mundo tipicamente nacionalista. Sua preocupação é com a mãe França. Ele volta-se para esta terra que, segundo ele, é a maior de todas, e que tem a missão de explicar os ideais de liberdade a todos os outros povos. Seus livros só podem ser compreendidos a partir desse nacionalismo. Assim, atesta Felix Gilbert: "In the second half of the nineteenth century the work of the cultural historian became more precise (...) was increasingly influenced by Romanticism and nationalism." (GILBERT , 1990, p.83)

Isso é, em verdade, aquilo que faz Michelet tão importante para Febvre. Este ministrava seu curso sobre Michelet na França de 1942, durante a ocupação nazista. A cultura alemã, que dominava o país coercitivamente, devia ser rejeitada. A Guerra abalava as estruturas do cotidiano, da vida real. O que Febvre encontra em Michelet, é uma forma de supremacia francesa dentro da tradição historiográfica. Abordar o romantismo de Michelet, como pai do conceito de Renascença e representante de uma forma de pensar própria aos franceses, é uma forma de resistência aos alemães e ao próprio romantismo alemão. Michelet é o romântico que traz valores do individualismo francês, e que prega a recuperação da tradição, quando massacrada por valores estranhos.

Assim, Febvre defende um romantismo originalmente micheletiano, sem se preocupar que, em face ao Renascimento, Michelet, mesmo tendo uma obra original, não deixa de pertencer ao movimento geral do romantismo, que assolou toda a Europa oitocentista. Assim, devemos tomar cuidado com as palavras de Febvre, pois se assim não o fizermos corremos o risco de desprezar grande parte da historiografia do século XIX, como a de Ranke, Droysen e Burckhardt. O historicismo romântico do século XIX é passível de comparações tanto na França de Michelet como na Suíça de Burckhardt. Pode-se afirmar que, no corpo do Romantismo, o conceito de Renascença parte de um contexto europeu do pós-guerras napoleônicas, tanto em Michelet, como, por exemplo, em Burckhardt. O volume 
Renaissance, de Michelet, sai em 1855. A Civilização do Renascimento Italiano de Burckhardt foi editado em 1860. Assim, mesmo com todo o mérito de Michelet, o conceito de Renascença não é só dele, ou só de Burckhardt, mas faz parte das atitudes intelectuais de vários homens dentro do contexto europeu do século XIX. O que mais importa aqui é o papel Michelet atribui ao historiador no processo do renascer de um povo e que pode ser visto através de Febvre. $\mathrm{Na}$ interrelação entre o fenômeno da Renascença em Itália e seu choque com a França, Michelet faz nascer uma visão universalista do Renascimento como evento que age mundialmente.

"Havia na Europa do século XV uma região privilegiada. Uma região abençoada, dois séculos a frente de seus vizinhos. Essa região era a Itália. De toda as regiões circunvizinhas, ainda a mais avançada relativamente era a França. Mas era pouco, em comparação com a Itália!" .(FEBVRE, 1994, p. 197)

Nesta perspectiva, a França estava imersa na barbárie, enquanto a Itália brilhava, porém num "belo dia" houve

“(...) uma revolução européia, uma revolução total porque um jovem rei e um exército jovem, dotados de um vivo impulso de mocidade e de instinto, saltaram com ímpeto de alegria e bárbaros a barreira dos Alpes?(...) 'Aqui a França inteira, uma pequena França completa foi leva da à Itália, visitou-a, sentiu-a e assimilou, por esse singular magnetismo (...)" (idem, p. 199)

O nacionalismo inflamado de Michelet propõe a contraposição de dois locais totalmente distintos: a França Medieval e a Itália Moderna, mas é isto que torna possível o Renascimento micheletiano. Portanto, coloca mais uma vez Febvre: 
"A Renascença nasceu do choque da França de Carlos VIII contra a Itália dos Bórgia (...) Ela nasceu, pois, necessariamente, na França? Michelet concorda que sim. Ele o diz expressamente. Mas então, e as outras nações: foi da França que elas tomaram a Renascença? (...) a França cadinho em que se elaborou a Renascença, foi depois a iniciadora da Europa (...)a França órgão vivo da Renascença." (ibdem, p. 221-222)

Quando a Itália foi dominada pelos Turcos, a responsabilidade de disseminar o Renascimento pela Europa passou para a França, já que o outro grande Império da Europa, a Espanha, estava submerso no radicalismo da Reforma Católica. O romantismo de Michelet, o coloca, enquanto historiador, irremediavelmente acorrentado a sua França. É dentro desta ótica que constrói sua Renascença. Não existe sentido nesta palavra se ele não puder enxergar este fenômeno veiculado por sua terra.

Michelet escreve sobre o Renascimento como se este fosse uma outra Revolução Francesa, anterior a própria Revolução do século XVIII. Para ele o ímpeto revolucionário francês foi responsável pela europeização da Renascença. Enquanto no século XVI, toda a Europa desenvolvida, inclusive a Itália, mergulhava nas brumas das Reformas, a França "não foi absorvida. Muito pelo contrário...ela permaneceu a mesma para a salvação da Europa e do espírito humano" (MICHELET in.: ibdem, p. 222)

Em Michelet todos os esforços se voltam para a busca de recuperação desta tradição missionária dos franceses, cortada pelos eventos posteriores às guerras napoleônicas. $O$ egoísmo capitalista invadiu a França, segundo Michelet, sufocando os ideais revolucionários. O poder revolucionário é uma característica privilegiada do Espírito Francês. Os ideais da revolução não deveriam ter sido esquecidos, mas devem renascer no século XIX, bem como serem disseminados pelo 
mundo. Como a França propagou o Renascimento, deve transmitir o segredo da Revolução. É a tradição universalista da França. O conceito de Renascimento em Míchelet se combina com aquilo que diz em "O Povo".

"Roma não esta em parte alguma a não ser aqui (...) a França foi o pontíficie da era das Luzes. Isso não é um acidente dos últimos séculos, um acaso revolucionário. É o resultado legítimo de uma tradição ligada a uma tradição de dois mil anos(...) As outras histórias são mutiladas, só a nossa é inteira; tomais a história da Itália, faltam-Ihe os últimos séculos; tomais a história da Alemanha, faltam-Ihe os primeiros. Tomai a França: por meio dela, ficais conhecendo o mundo"(MICHELET, 1988, p.209)

O conceito micheletiano de Renascimento só pode ser visto a partir do espírito revolucionário de seu povo, capaz de fazer a força transformadora dos homens ressurgir. É importante ressaltar que a afirmação de que algo precisa ressuscitar reflete que esta mesma coisa jaz morta. A questão colocada por Michelet é a ausência de concretude das vontades transformadoras nos espíritos humanos de sua época. Michelet expõe, assim, como historiador, uma necessidade do mundo oitocentista: a fé nos homens. Neste sentido, a História, segundo ele, deve atuar como mestra para a vida, propondo a prática educativa ou a crítica, mas sempre apontando a ausência de um sujeito humano que age em seu mundo contemporâneo. É isto o que ele faz ao abordar o conceito de Renascimento europeu centrado na França, que revoluciona todo seu continente transmitindo aquilo que foi criado na Itália. Ele busca renovar a força de seu povo, mostrando do que foi responsável no passado.

Segundo Guisburg: "O Romantismo é um fator histórico e, mais que isso, é o fato que assinala, na história da consciência humana, a relevância da consciência histórica."(GUINSBURG, 
1993, p.14) Isto pode ser verificado na esperança de Michelet quanto à eficácia da história para a vida prática. Ou seja, o cerne de sua obra é historicista. Porém, antes de nos aventurarmos por este caminho, devemos deixar claro que o historicismo aqui utilizado não é aquele que se refere a uma concretude da História, no sentido que denota uma realidade passada, realidade esta apreensível ou não, porém dada. O historicismo do qual se fala é aquele que tem origem no Romantismo Alemão, que postulava conceitos que se contrapunham à idéia de História lluminista e Cientificista. É um tipo de abordagem que traz a história como produto da ação humana, o que permite observar a própria vida como criadora de uma história que advêm da liberdade do homem, e da individualidade dos sujeitos históricos. Este conceito também é denominado em alguns locais de historismo para diferir do historicismo citado acima. Num quadro ligado a uma noção clássica de romantismo, que cria uma escrita historicista, não é só o nacionalismo que dá corpo às idéias de Michelet. Conceitos como de Espírito de um Povo, Gênio, natureza divinizada, individualismo e tradição, atravessam sua obra. Assim, em Michelet, podemos ver vertentes próprias do Romantismo Alemão numa montagem híbrida com a conjuntura francesa do século XIX.

Todos os conceitos do historicismo em Michelet se voltam para a recuperação do povo francês. Assim, ele se outorgará a figura do Gênio Romântico. Os objetivos práticos de sua escrita denotam a concepção que ele tem de si enquanto um homem de gênio. Segundo aquilo dito em "O Povo", a escrita da História deve ter uma dimensão pedagógica, que é levar o povo francês a se enxergar como unidade coletiva, capaz de não se submeter a uma sociedade mecanizada, própria da era industrial e burocratizada (era do maquinismo), e recuperar seu potencial transformador. Isso se tornará possível através do amor ao próximo e à pátria. É a ação do indivíduo que o encaminha para outros e para a nação, pois sobre o homem individual se ergue o indivíduo nação. 
Neste sentido, o historiador deve ser o condutor, pedagogo maior na formação de seu povo. O historiador é o "homem duplex", capaz de unir o mundo dos simples, da natureza e do popular, à linguagem do mundo reflexivo, do homem culto. Só assim, a missão de Michelet, que é uma missão de amor, se efetivará. $O$ universalisrno francês e o individualisrno do romantismo nacionalista se combinam de forma impressionante em Michelet. É por isso que ele consegue ver unidade na História da França. Só ali, ele concebe, como em si mesmo, a tarefa pedagógica do gênio. Enquanto o historiador é o gênio de seu povo, a França é o gênio das nações. Ao historiador Michelet cabe ensinar ao povo, à França cabe ensinar o valor dos homens e da liberdade a outras nações.

É nesse universalismo que devemos centrar nossa idéia de globalidade e síntese da História em Michelet. Enquanto o nacionalismo francês é o vetor de sua obra, ele outorga-se a tarefa de reensinar ao povo sua tradição universalista, que trará liberdade às outras nações. Quando rejeita a Igreja, não rejeita uma visão religiosa romântica. Para ele, Deus se manifesta na obra do povo francês. Assim, a Renascença é sempre França, o que não tem necessariamente relação com o Renascimento Italiano, mas sim com a difusão de que o homem individual e ativo deve renascer sempre, em cada parte da História. Esta é a pedagogia micheletiana, que personifica a esperança.

Michelet, influenciado por Vico, e pela idéia de organicidade das partes individuais, acredita na continuidade entre Idade Média, Renascença e Revolução Francesa. O laço que une estas três épocas é o Espírito do Povo, fator essencial para a unidade dos dois mil anos História da França, como foi citado. Deus se manifesta no povo, é a Cidade dos Homens que vai aos poucos sendo construída pelos franceses, não só para a França, mas para o mundo inteiro. Assim, Michelet vê a morte e sobrevivência das épocas umas nas outras. Elas se superam, mas sempre permanece algo de uma na outra. É o mistério da História constituída por um povo. Mistério este que 
deve ser respeitado pelo historiador como inefável. Embora ele diga que a busca da cultura, como existiu na Itália, acabe sendo sufocada pelas guerras religiosas na França, a sabedoria do Espírito do Povo, que reflete o Espírito de Deus, continua eficaz na História. "...Fechei os livros e voltei ao seio do povo tanto quanto era possível' (MICHELET, 1988, p.3) Observa-se, assim a supremacia do povo em relação ao espírito culto. O povo é o depósito da sabedoria divina. Isso é que o faz cumprir a sagrada missão de propagar a liberdade em todas as terras, num renascimento perpétuo.

Assim, embora o Renascimento em Michelet seja a cultura italiana propagada pela França, o espírito francês se sobrepõe. A reflexão da Itália só pode se perpetuar conjugada ao espírito do povo francês, na união do simples com o reflexivo. Portanto, no Renascimento se concretiza a tarefa missionária do povo. Essa tarefa, que existe desde da Idade Média, desde de Joana D'arc, é a missão do povo francês, preenchido de amor e compaixão autênticos.

A escrita de Michelet tem como objetivo construir um todo organizado de acordo com a História de sua nação, onde Idade Média e Moderna demonstram a capacidade daqueles franceses, que não devem nunca esquecer de seu potencial revolucionário. Michelet é o pedagogo que visa redespertar a consciência dos trabalhadores de seu tempo. As máquinas do século XIX propõem um mundo de ação sem reflexão. O povo acaba por se desconhecer. Ao historiador cabe recriar a fé dos homens em si mesmos. Sem fé não há educação, não há a reflexão. $O$ historiador deve estimular a força de fé nos ideais Revolucionários, e não num conceito de Razão que domina a Vontade. Esta é a tarefa dos historiadores para Michelet, que vê na sua pátria a iniciação da pátria universal. O renascimento de França é um renascimento global, diante do mundo decante do século XIX.

Em "O Povo" isto está claro. O historiador é o homem de gênio em quem se manifestam os anseios coletivos. A sociedade 
de massas é aquela que acaba com a individualidade. É a ela que se deve resistir. Em Michelet deve ser recuperada singularidade do espírito de seu povo, sua tradição. O espírito francês que ao ser massificado, mecanizado, derruba todo um ideal de liberdade. Ao ser reensinado este ideal se difundiria para os outros povos, mediante a tarefa salvífica da França. Ou seja, seria a liberdade universal propagada. Ora, assim sendo, a noção de Renascimento nesse historiador é uma perspectiva para toda a História. O Renascimento é o conceito que torna possível a reflexão sobre própria época do historiador. $O$ Renascimento é possível ou não no XIX? O Renascimento como espírito humano pode se reerguer frente à despersonalização?

Esta pergunta, em Michelet, é respondida através da idéia de que a educação do povo o faria resistir ao nascimento de um Estado burocrático e técnico, que abandonava o valor do homem submetendo-o à máquina. Ou seja, a conscientização histórica e a recuperação das tradições se voltariam contra um Estado que domina os agentes em prol de uma liberdade retórica, que na verdade aprisionaria o cidadão comum.

Para Michelet, sua obra historicista resiste ao despersonalismo, e deve afastar-se da ciência que iguala, sob leis, toda a singularidade. Portanto, mesmo que seu olhar estivesse voltado para a França, a partir dele abre-se uma perspectiva de História que valoriza todas as vidas nacionais e individuais. Seu historicismo remete-se às particularidades, tanto no que diz respeito às diversas culturas, como aos agentes particulares. Assim, sua mensagem volta-se para todo e qualquer historiador que pensa sobre sua própria atividade, diante de qualquer povo. Este toma para si um papel. É a História que busca refletir sobre seu próprio sentido. É o historiador que procura para si um papel no mundo através da escrita. Porém, sua atuação se dá não somente ao nível da escrita, mas sim das formas práticas que esta escrita assume diante do mundo. É o papel do gênio romântico. O historiador-pedagogo deve ser capaz de ser a interface entre o povo e o mundo reflexivo. Sendo 
assim, constrói a sua tarefa diante do mundo, pois não é apenas um intelectual, mas apresenta em seu trabalho uma dimensão ético-política que não poderá, em momento algum, ser ignorada. Por isso, é tentador tomar de Michelet seu otimismo, sem no entanto deixar de cita-lo ao fim da vida:

"Se abrirem meu coração depois de minha morte ler-se-á nele a idéia que me acompanhou: 'Como virão só livros populares?' Oh problema! Ser velho e jovem, ao mesmo tempo, ser um sábio e um menino! Remoí esses pensamentos ao longo de toda minha vida. Eles se apresentavam sempre e me prostavam. Então eu senti nossa miséria, a impotência dos homens de letras, dos sutis. Eu me desprezava. Nasci povo, tinha o povo no coração... pude, em 46 [1846- data de escrita de "O Povo"], estabelecer o direito do povo mais do que nunca se fez... Mas sua língua, sua língua me era inacessível. Não consegui fazê-lo falar." (MICHELET, Histoire de France, citado in: VIALLANEIX, $P$. Introdução de "O Povo", 1988, p. XLII)

De qualquer modo, a análise de Febvre demonstra um século depois, que Michelet se julgou com muita severidade. $\mathrm{O}$ encontro de Febvre com Michelet, durante as contrariedades da guerra, na análise do Renascimento, acaba por provocar o que o próprio Michelet objetivava com sua obra: ressuscitar os homens do passado em prol dos agentes do presente. 


\section{Bibliografia}

FEBVRE, Lucien. Michelet e a Renascença. São Paulo: Editora Página Aberta Ltda, 1995.

GILBERT, Felix. History: Politics or Culture. Princeton: Princeton University Press, 1990.

GUINSBURG, J. O Romantismo. São Paulo: Editora Perspectiva, 1993.

LÖWITH, Karl. O sentido da História. Lisboa: Edições 70, 1991. LÖWY e SAYRE, Michael e Robert. Romantismo e Política. São Paulo: Paz e Terra, 1993.

MICHELET, Jules. O Povo. São Paulo: Martins Fontes, 1988. WHITE, Hayden. Meta-História. SãoPaulo: EDUSP, 1992.

Abstract: Through the concepts of Renascence and People in Jules Michelet's work, it is possible to think about links between the historian's activities and the forms to write a responsible and useful History. This article aims to make a reflection on the influences of the romantic historicism in Michelet and his idealization of the historian as a pedagogue able to teach self-esteem and the value of tradition.

Keywords: Jules Michelet, Lucien Febvre, Renascence, romantic historiography, pedagogic action. 